\title{
Some consequences of different older driver licensing procedures in Australia
}

\author{
Jim Langford, Monash University Accident Research Centre \& Tasmanian \\ Department \\ of Infrastructure, Energy and Resources. \\ Michael Fitzharris, Monash University Accident Research Centre. \\ Stuart Newstead, Monash University Accident Research Centre.
}

Given both the expected growth in the number of older drivers and their over-involvement in fatal and serious injury crashes, there has been a world-wide call for improved licensing procedures to manage older driver safety. In particular, licensing authorities have been urged to move from mandatory assessment of all older drivers to assessment practices targeting only those at higher crash risk.

The current study has examined older driver fatal and serious injury crash rates across all Australian States, to determine a possible association with the different licensing procedures. In particular, crash rates in Victoria (whether there is no age-based assessment program) have been compared with rates in other jurisdictions that have such programs. Rates have been calculated using two denominators: per population and per number of licensed drivers. A third rate based on per distance travelled was attempted but had to be abandoned due to the high error ranges associated with the measurements.

Some data limitations notwithstanding, older drivers in jurisdictions with age-based mandatory assessment programs could not be shown to be safer than drivers in Victoria. Further, the available evidence indicates that older drivers in Victoria may have a significantly safer record regarding overall involvement in serious casualty crashes. The next task is to strengthen the conclusions drawn from the current set of analyses by developing a third level of comparison, based on the distances driven by older drivers in each jurisdiction. This will require a special-purpose survey to produce travel data with sufficiently narrow confidence intervals to allow meaningful comparisons 